\title{
Conservative management of pituitary tumor apoplexy
}

\author{
Tratamento conservador da apoplexia pituitária
}

Antonio Benigno A. Santos', Mariana M. França', Renata M. Hirosawa', Mônica Marivo', Marco A. Zanini² ', Vania S. Nunes'

\section{SUMMARY}

Pituitary tumor apoplexy is a rare neuroendocrine syndrome resulting, in most cases, from hemorrhage or infarctation of a pre-existing pituitary adenoma. Treatment recommendations vary; some authors advocate urgent surgical decompression of the tumor, whereas others suggest that conservative management can lead to recovery of neuro-ophthalmologic function. We describe two patients with pituitary tumor apoplexy who had clinically non-functioning macroadenomas and hypopituitarism, including hypogonadism. They were treated conservatively without surgery, and achieved tumor remission. Arq Bras Endocrinol Metab. 2011;55(5):345-8

\section{SUMÁRIO}

A apoplexia pituitária é uma rara síndrome neuroendócrina causada, na maioria dos casos, pela hemorragia ou enfarte de um adenoma pituitário preexistente. 0 tratamento recomendado é variável; alguns autores defendem a descompressão cirúrgica do tumor em regime de urgência, enquanto outros sugerem que o tratamento conservador pode levar à recuperação da função neuroftalmológica. Descrevemos os casos de dois pacientes com apoplexia pituitária que apresentaram macroadenomas clinicamente não secretores e hipopituitarismo, incluindo hipogonadismo. Ambos foram submetidos ao tratamento conservador, sem cirurgia, e houve a remissão do tumor. Arq Bras Endocrinol Metab. 2011;55(5):345-8

1 Department of Clinical Medicine, Botucatu Medical School, Universidade Estadual Paulista

(Unesp), Botucatu, SP, Brazil

${ }^{2}$ Department of Neurology, Psychiatry and Psychology, Botucatu Medical School, Unesp, Botucatu, SP, Brazil

Correspondence to: Vania dos Santos Nunes vsnunes@fmb.unesp.br

Received on Dec/22/2010 Accepted on Apr/24/2011

\section{INTRODUCTION}

P ituitary tumor apoplexy is a rare neuroendocrine syndrome resulting, in most cases, from hemorrhage or infarctation of a pre-existing pituitary adenoma. The diagnosis is based more on clinical findings than on pathological examination, and therefore should only apply to patients with signs and symptoms of meningeal irritation or of compression of structures proximal to the sella turcica (1).

Prevalence of pituitary tumor apoplexy has been hard to determine, principally because it is underdiagnosed. In the majority of the epidemiological surveys, percentage of patients with the condition was calculated from the number of patients treated with surgery. Prevalence varies between $0.6 \%$ and $10 \%$, usually $<5 \%$, with a mean of $2 \%$ of all surgically resected adenomas (2).
The pathophysiological mechanism involved in the genesis of apoplexy remains unclear, and it is unknown whether it involves primary hemorrhage or hemorrhagic infarctation. The size of the adenoma appears to be the greatest risk factor; patients with macroadenomas (tumors $>1 \mathrm{~cm}$ ) are more likely to develop this complication than patients with microadenomas (tumors $<1$ $\mathrm{cm})(2-4)$. The reason for this difference remains unknown. Morphologically, the vessels of a pituitary adenoma display characteristics of incomplete maturation and poor fenestration, and their basal membranes are often ruptured (5). These structural abnormalities can contribute to susceptibility to spontaneous hemorrhage, and therefore represent a potential mechanism for the occurrence of apoplexy (1).

In $60 \%$ to $80 \%$ of cases, pituitary tumor apoplexy has occurred spontaneously in an asymptomatic pa- 
tient with no previous history of pituitary adenoma. However, several triggering factors have been described in $25 \%$ to $30 \%$ of cases, including cranial trauma, hypotension, anticoagulants, diabetes mellitus, thrombocytopenia, dopamine agonists, surgeries, radiotherapy, hypertension, and dynamic testing of the hypothalamo-pituitary-adrenal axis $(1,6)$.

Clinical presentation of pituitary tumor apoplexy varies, and includes neurological and endocrinological signs and symptoms, with headache being the most frequent complaint (63\% to $100 \%$ of cases), followed by visual deficits ( $40 \%$ to $100 \%)$, cranial nerve paralysis, nausea, and vomiting (1). Less common symptoms include decreased level of consciousness and, rarely, meningeal signs. The headache can occasionally be generalized, but in most instances it is retro- or peri-orbital, and is not necessarily associated with subarachnoid hemorrhage or tumor enlargement in the pituitary (6). The mechanisms involved in the occurrence of headache include meningeal irritation, pressure on the dura-mater, pituitary enlargement, or involvement of the trigeminal nerve within the cavernous sinus (3).

Patients may also present with symptoms of hypopituitarism associated with signs of hormonal hypersecretion dependent on the type of pituitary adenoma. The most important hormonal deficit in clinical terms is adrenocorticotropic hormone (ACTH) deficiency, because it results in glucocorticoid deficiency, having adverse consequences in stressful conditions such as apoplexy. The majority of patients present at least partial hypopituitarism. Diabetes insipidus is reported in only $4 \%$ of cases, and inappropriate antidiuretic hormone secretion syndrome also occurs rarely.

The best method for diagnosing hemorrhage within a pituitary adenoma is magnetic resonance imaging (MRI), although cerebral computed tomography (CT) has also been used (7).

The role of surgery in the treatment of pituitary tumor apoplexy is still controversial. Some authors recommend urgent surgical decompression of the tumor, while others suggest that recovery of neuro-ophthalmologic function can occur when decompression is delayed. A retrospective analysis has indicated that delay in surgical decompression resulted in positive outcomes in some cases, particularly in stable patients with no evidence of progression of visual changes (8).

Here, we describe two patients with clinically nonfunctioning pituitary macroadenomas who developed pituitary tumor apoplexy that was treated conservatively.

\section{CASE REPORTS}

\section{Case 1}

A 38-year-old male patient was admitted to the Clinical Hospital of Botucatu Medical School because of a sudden intense headache in the frontal and retroocular regions, accompanied by nausea and vomiting, and a 3 -week history of "blurred vision". Physical examination showed bitemporal hemianopsia and paralysis of the left sixth cranial nerve, but was otherwise unremarkable. His past medical history was also unremarkable.

Cranial computed tomography revealed a pituitary tumor with compression of adjacent structures. Pituitary MRI demonstrated a solid expansive process (3.0 x $2.9 \mathrm{~cm}$ ) with hypersignal on Tl-weighted images, supra- and para-sellar extension, and optic chiasm compression, findings compatible with pituitary macroadenoma and apoplexy (Figure 1). Laboratory test results showed central hypocortisolism (basal cortisol 1.21 $\mu \mathrm{g} / \mathrm{dL}$, reference value [RV]: 5-25 $\mu \mathrm{g} / \mathrm{dL}$ ), hypogonadism (total testosterone $<20 \mathrm{ng} / \mathrm{dL}, \mathrm{RV}$ : 181-758 $\mathrm{ng} / \mathrm{dL}$; luteinizing hormone $[\mathrm{LH}] 0.28 \mathrm{mUI} / \mathrm{mL}$, $\mathrm{RV}$ : $0.8-7.6 \mathrm{mUI} / \mathrm{mL}$; follicle stimulating hormone [FSH]: $0.67 \mathrm{mUI} / \mathrm{mL}, \mathrm{RV}: 0.7-11.1 \mathrm{mUI} / \mathrm{mL}$ ), and central hypothyroidism (thyroid stimulating hormone [TSH] $0.05 \mu \mathrm{IU} / \mathrm{mL}, \mathrm{RV}: 0.4-4.0 \mu \mathrm{IU} / \mathrm{mL}$; free T4: $0.51 \mathrm{ng} / \mathrm{dL}, \mathrm{RV}: 0.8-1.9 \mathrm{ng} / \mathrm{dL}$ ), without hypersecretion of other hormones (growth hormone [GH] 0.14 $\mathrm{ng} / \mathrm{dL}, \mathrm{RV}:$ 0-5 ng/dL; insulin-like growth factor 1 IGF- 1 - and prolactin in normal ranges).

The patient was treated conservatively with intravenous hydrocortisone, hydration, and analgesics. He was hospitalized for 20 days and remained clinically stable, with no progression of neurological deficits. After 3 months, the patient's visual deficits and central hypogonadism were resolved. His visual fields were normal, total testosterone was $479 \mathrm{ng} / \mathrm{dL}$, and repetition of the MRI demonstrated normal pituitary gland (1.0 $0.9 \times 0.8 \mathrm{~cm}$; Figure 2). He was maintained on levothyroxine treatment, but corticosteroid replacement therapy was discontinued to see if the deficit was resolved. Hormone replacement restarted few months later, when the patient presented symptoms of adrenocortical deficiency and low basal cortisol level.

Two years later, the patient still needs thyroid and corticosteroid replacement therapy, but his pituitary MRIs have been normal, and he remains free of headaches and visual deficits. His gonadotropic axis also remains normal (total testosterone: $521 \mathrm{ng} / \mathrm{dL}$ ). 


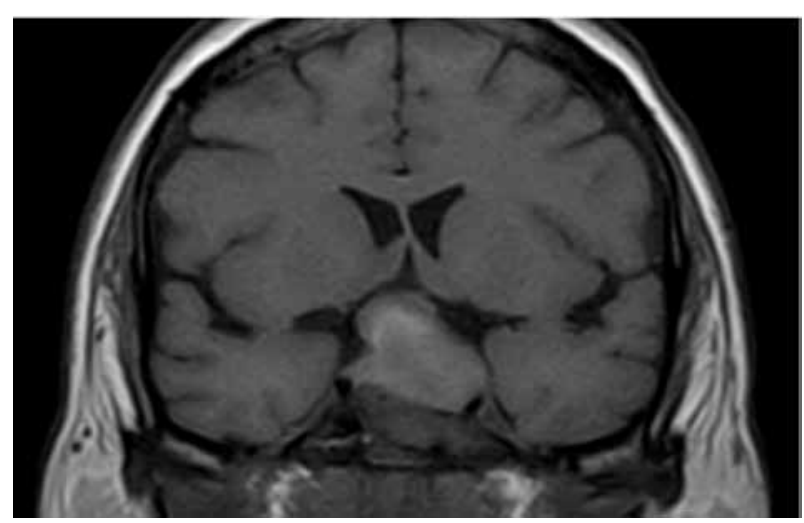

Figure 1. Macroadenoma of pituitary gland, with supra- and para-sellar extension, compression of the optic chiasm and signs of hyperdensity suggestive of hemorrhage. Patient 1.

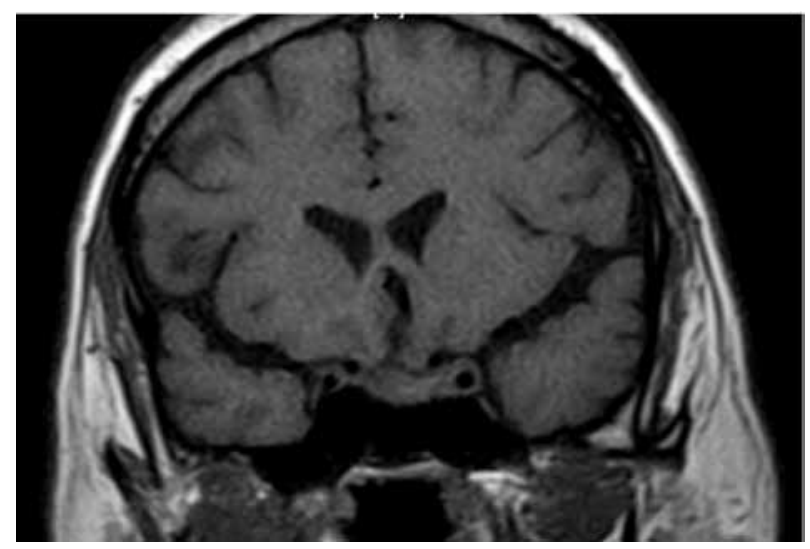

Figure 2. MRI demonstrating remission of sellar lesion. Patient 1.

\section{Case 2}

A 75-year-old male patient was admitted to the Clinical Hospital of Botucatu Medical School with a 3-day history of sudden-onset frontal and right parietal headache. He also had a 6-month history of protrusion of his right eye, reduced libido, and excessive somnolence, and an 1-year history of arterial hypertension, controlled by medication. Physical examination revealed proptosis and blindness of the right eye, and no other abnormal findings.

MRI showed a pituitary tumor $(2.3 \times 1.8 \times 1.9 \mathrm{~cm})$ with supra-sellar expansion, compression of the optic chiasm, and hypersignal on Tl-weighted images, findings compatible with pituitary macroadenoma apoplexy (Figure 3). Laboratory test results indicated central hypocortisolism (basal cortisol $1.1 \mu \mathrm{g} / \mathrm{dL}, \mathrm{RV}: 5-25 \mu \mathrm{g} /$ $\mathrm{dL}$ ), hypogonadism (total testosterone $<20 \mathrm{ng} / \mathrm{dL}$, RV: $181-758 \mathrm{ng} / \mathrm{dL}$; LH $1.29 \mathrm{mUI} / \mathrm{mL}, \mathrm{RV}$ : 0.8-7.6 $\mathrm{mUI} / \mathrm{mL}$; FSH $3.58 \mathrm{mUI} / \mathrm{mL}, \mathrm{RV}: 0.7-11.1 \mathrm{mUI} /$ $\mathrm{mL}$ ), and central hypothyroidism (TSH $0.31 \mu \mathrm{IU} / \mathrm{mL}$,
RV: 0.4-4.0 $\mu \mathrm{IU} / \mathrm{mL}$; free T4 $0.7 \mathrm{ng} / \mathrm{dL}, \mathrm{RV}: 0.8$ $1.9 \mathrm{ng} / \mathrm{dL}$ ), without hypersecretion of other hormones (GH $0.4 \mathrm{ng} / \mathrm{dL}, \mathrm{RV}: 0-5 \mathrm{ng} / \mathrm{dL} ; \mathrm{IGFl}$ and prolactin in normal ranges).

The patient was treated conservatively with intravenous hydrocortisone, hydration, and analgesia, and levothyroxine supplementation began. He had no progression of neurological deficits and elective surgery was delayed. Two months later, he presented complete resolution of both his right eye proptosis and central hypogonadism, but still had amaurosis of the right eye. MRI showed regression of the adenoma ( $1.7 \times 1.3 \times$ $1.1 \mathrm{~cm})$ and it no longer compressed the optic chiasm. Conservative treatment, consisting of levothyroxine and corticosteroid replacement therapy, continued. Ten months after admission, MRI showed further regression of the adenoma $(0.9 \times 0.8 \times 0.9 \mathrm{~cm}$; Figure 4$)$.

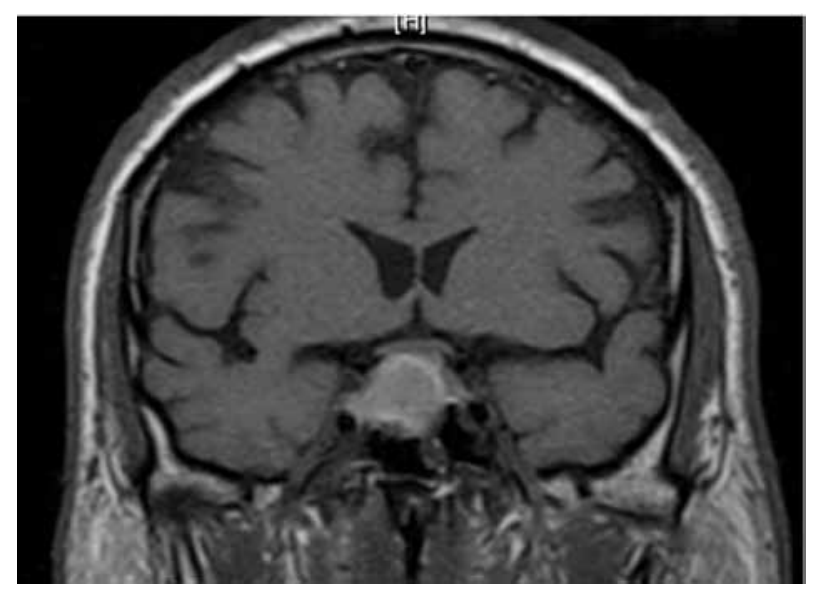

Figure 3. MRI showing a pituitary tumor, measuring $2.3 \times 1.8 \times 1.9 \mathrm{~cm}$, with supra-sellar expansion and compression of the optic chiasm, hypersignal in T1-weighted image, and signs of hyperdensity suggestive of hemorrhage. Patient 2.

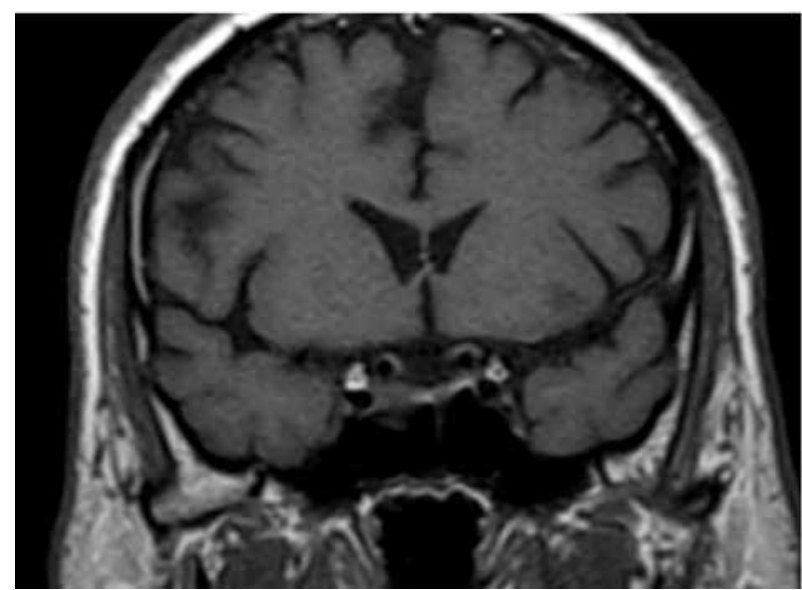

Figure 4. MRI demonstrating remission of sellar lesion. Patient 2. 
Two years later, the patient still needs thyroid and corticosteroid replacement therapy, but his hypogonadism remains in remission (free $\mathrm{T} 4 \mathrm{l} .1 \mathrm{ng} / \mathrm{dL}$, total testosterone $311 \mathrm{ng} / \mathrm{dL}$ ). He is still blind in the right eye. Follow-up pituitary MRI findings are compatible with empty sella.

\section{DISCUSSION}

Morbidity and mortality of patients with pituitary tumor apoplexy have declined over the past 6 decades. Factors that may have contributed to this include improvement in diagnostic accuracy, more sophisticated therapeutic support, use of glucocorticoids, and refinement of surgical and postoperative techniques (1). Untreated patients may continue to have high morbidity and mortality; before the use of glucocorticoids, mortality was approximately $50 \%(1)$.

Patients with signs and symptoms of pituitary tumor apoplexy require thorough clinical evaluation and continuous monitoring to care for their neurological, ophthalmological, and endocrine dysfunctions. After hemodynamic stabilization and glucocorticoid replacement, it is important to choose the best treatment option for the improvement or stabilization of the patient's neuro-ophthalmological deficits. Immediate surgical intervention for apoplexy remains controversial. Several reports showed that spontaneous neurological recovery is possible, and some authors reported that patients treated conservatively had neurological and neuro-ophthalmological recovery rates similar to those of patients treated surgically (9). Other more recent retrospective studies have also provided evidence that nonsurgical treatment of patients with pituitary tumor apoplexy may be safe for patients who do not present visual deficits or show early evidence of recuperation from this condition $(10,11)$. On the other hand, results of trans-sphenoid decompression immediately after stabilization of the patient have been very good, and recovery of neurological and pituitary function occurs within a period of several hours to days.
The two patients reported here achieved tumor remission with conservative treatment. One recovered completely from his visual deficit, and both showed normalization of at least one of the compromised pituitary hormone axes.

New studies with methodologies appropriate for clinical decision-making are needed to determine the optimal time for surgical intervention in the treatment of pituitary tumor apolexy. Until then, the decision must be individualized, using a multidisciplinary approach that encompasses all aspects of the patient's clinical condition.

Disclosure: no potential conflict of interest relevant to this article was reported.

\section{REFERENCES}

1. Nawar RN, AbdelMannan D, Selman WR, Arafah BM. Pituitary tumor apoplexy: a review. J Intensive Care Med. 2008;23(2):75-90.

2. Verrees M, Arafah BM, Selman WR. Pituitary tumor apoplexy: characteristics, treatment, and outcomes. Neurosurg Focus. 2004;16(4):E6.

3. Bills DC, Meyer FB, Laws ER Jr, Davis DH, Ebersold MJ, Scheithauer BW, et al. A retrospective analysis of pituitary apoplexy. Neurosurgery. 1993;33(4):602-8; discussion 8-9.

4. Rolih CA, Ober KP. Pituitary apoplexy. Endocrinol Metab Clin North Am. 1993;22(2):291-302.

5. Schechter J. Ultrastructural changes in the capillary bed of human pituitary tumors. Am J Pathol. 1972;67(1):109-26.

6. Chang CV, Felicio AC, Toscanini AC, Teixeira MJ, Cunha-Neto MB. Pituitary tumor apoplexy. Arq Neuropsiquiatr. 2009;67(2A):328-33.

7. Post MJ, David NJ, Glaser JS, Safran A. Pituitary apoplexy: diagnosis by computed tomography. Radiology. 1980;134(3):665-70.

8. Sibal L, Ball SG, Connolly V, James RA, Kane P, Kelly WF, et al. Pituitary apoplexy: a review of clinical presentation, management and outcome in 45 cases. Pituitary. 2004;7(3):157-63.

9. Maccagnan P, Macedo CL, Kayath MJ, Nogueira RG, Abucham J. Conservative management of pituitary apoplexy: a prospective study. J Clin Endocrinol Metab. 1995;80(7):2190-7.

10. Ayuk J, McGregor EJ, Mitchell RD, Gittoes NJ. Acute management of pituitary apoplexy--surgery or conservative management? Clin Endocrinol (Oxf). 2004;61(6):747-52.

11. Gruber A, Clayton J, Kumar S, Robertson I, Howlett TA, Mansell P. Pituitary apoplexy: retrospective review of 30 patients--is surgical intervention always necessary? Br J Neurosurg. 2006;20(6):379-85. 